\title{
Unusual presentation of infective endocarditis with cerebral infarction in a neuro-trauma patient
}

\author{
US Perera ${ }^{*}$ \\ Consultant in Anaesthesia and Intensive care ${ }^{I}$, District General Hospital, Hambantota, Sri Lanka.
}

"Corresponding author: udeshsp2003@yahoo.com

\begin{abstract}
One of the devastating neurologic complications of infective endocarditis is middle cerebral artery territory cerebral infarction due to embolic events causing ischaemia. We encountered an interesting case of infective endocarditis complicated by cerebral infarction in a patient with traumatic brain injury who had undergone craniotomy a month before the event. His head injury and its complications mislead the possibility of early suspicion of infective endocarditis.
\end{abstract}

Keywords: infective endocarditis; cerebral infarction; embolic brain infarction; traumatic brain injury; craniotomy

\section{Introduction}

Infective Endocarditis (IE) may present with devastating neurologic consequences, often manifested as the first sign of illness ${ }^{1,2,3}$. The incidence of central nervous system (CNS) complications in infective endocarditis is $12 \%$ to $40 \%^{12,3,4,5}$. Embolic event is the most frequent CNS manifestation and significantly associated with Staphylococcus aureus infection ${ }^{1,7}$. Infective endocarditis-associated neurological complications have a mortality rate of about 20$25 \%$ in treated patients ${ }^{1}$. The neurological manifestations of the IE include embolic brain infarction, Transient ischaemic attacks (TIA), cerebral haemorrhage, meningitis, brain abscess, toxic encephalopathy, seizures, and headache ${ }^{1,3}$. Cerebral emboli commonly (>90\%) lodge in the distribution bed of the middle cerebral artery $(\mathrm{MCA})^{6.7}$. The highest incidence of embolic complications is seen with aortic- and mitralvalve infections ${ }^{2,7}$. Here we present a case of embolic brain infarction predominantly in the middle cerebral artery territory associated with infective endocarditis, which manifested a month after a head injury. His previous history of head injury and craniotomy and the nature of it unusual presentation might have had significant impact on the diagnosis and the final outcome.

\section{Case report}

A sixty nine year old gentleman was admitted to the surgical casualty unit of our District General hospital following sudden onset of loss of consciousness. His GCS on admission was 4/15; he was intubated and admitted to our multi disciplinary semi-open intensive care unit for further management.

A month before, he had undergone left temporoparietal craniotomy and evacuation of intracranial haematoma (ICH) causing a midline shift (MLS), following a road traffic accident. After surgery in a regional neurosurgical unit, he was transferred to our district General hospital for further care, and discharged home from the surgical ward two weeks later with a GCS of $11 / 15$.

On the current admission to the ICU, he was febrile $\left(101^{0} \mathrm{~F}\right)$, tachycardic $(130 / \mathrm{min})$ and hypotensive $(90 / 60 \mathrm{mmHg})$. Following investigation results were observed. White cell count (WCC) was $5550 / \mathrm{mm}^{3}$ with neutrophils (PNL) $86.1 \%$. Platelet count and serum creatinine were $74000 / \mathrm{mm}^{3}$ and $1.4 \mathrm{mg} / \mathrm{dL}$, respectively. International normalised ratio (INR) was 2.08 and prothrombin time was 21.6 seconds. Noncontrast CT brain did not show MLS or any significant changes from his post-operative CT (Figure 1). Intracranial infection, meningitis or encephalitis were the differential diagnosis and intravenous ceftriaxone $2 \mathrm{~g}$ twice a day and intravenous acyclovir 500mg thrice a day were started after taking blood and urine cultures. Intravenous noradrenaline infusion was started after giving fluid boluses and insertion of a central venous catheter. Patient was paralysed with atracurium, sedated with fentanyl and midazolam infusions, and ventilated for 48 hours. Despite the treatment, his WCC rose further to $15460 / \mathrm{mm}^{3}$, platelets dropped to $45000 / \mathrm{mm}^{3}$ and C Reactive Protein was $212 \mathrm{mg} / \mathrm{L}$. Platelet 
transfusion was given to keep the platelet count above $100,000 / \mathrm{mm}^{3}$.

Three days later his blood culture isolated multiresistant Staphylococcus aureus (MRSA) and tracheal secretions isolated coliforms. Intravenous vancomycin $1 \mathrm{~g}$ daily was added and ceftriaxone dose was increased to $2 \mathrm{~g} 8$ hourly. He also had evidence of right lower-lobe consolidation in the chest radiograph.

His urine output reduced and serum creatinine was $1.61 \mathrm{mg} / \mathrm{dl}$. Ultrasound scan (USS) revealed evidence of renal parenchymal disease, right sided pleural effusion and the consolidation of inferior lobe of the right lung. He had no evidence of pericardial effusions or abdominal collections. Repeated non contrast CT of the head revealed extensive right side cerebral infarction.

\section{(Figures 2 and 3)}

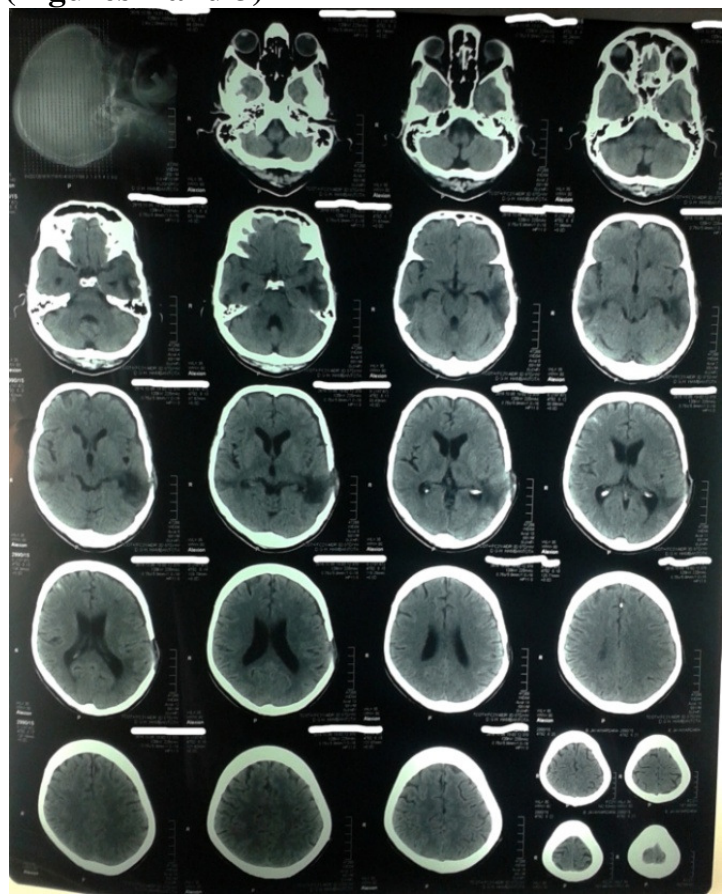

Figure 1.

Reviewing the CT scan and the condition of the patient, consultant neurosurgeon advised on conservative management. Meanwhile the patient was increasingly becoming septic with WCC rising to $27,500 / \mathrm{mm}^{3}$. He was also becoming more thrombocytopaenic and coagulopathic which needed further platelets, fresh frozen plasma and cryoprecipitate transfusions. On day 6 in ICU, he developed supraventricular tachycardia (SVT) with a heart rate exceeding
160 beats/min. Intravenous amiodarone $300 \mathrm{mg}$ was given and $900 \mathrm{mg}$ infusion started.

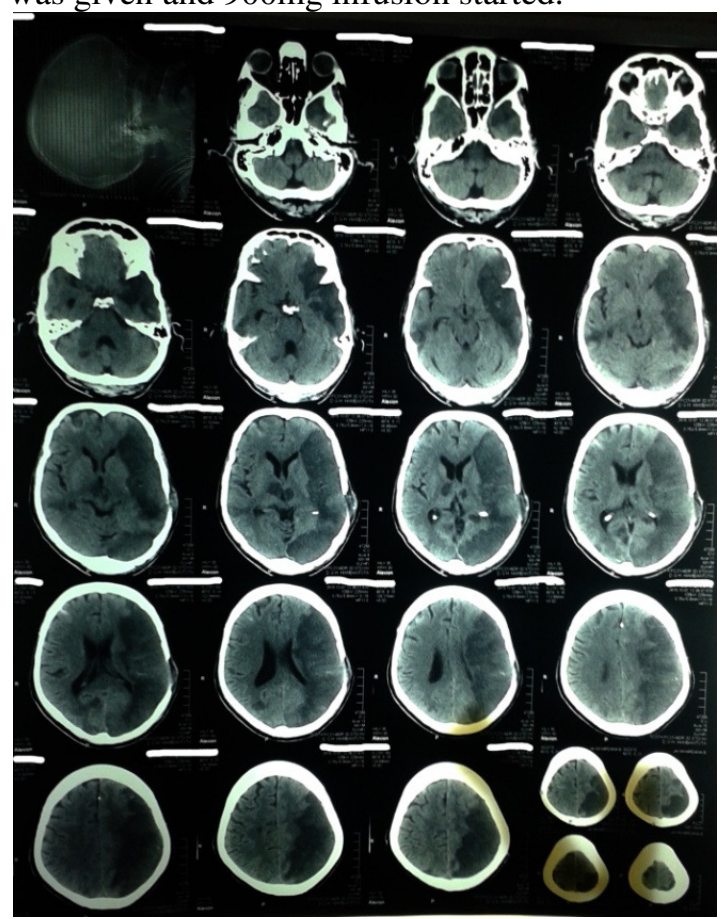

Figure 2

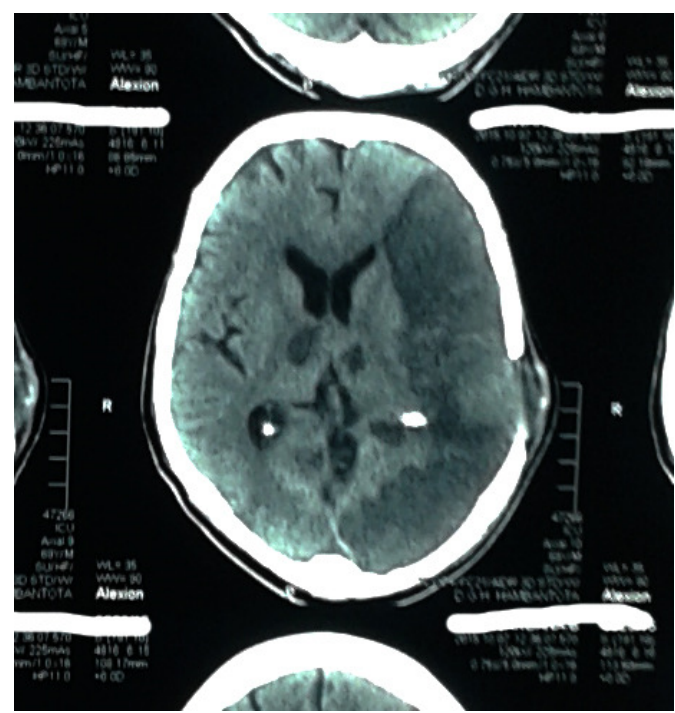

Figure 3

The following day, 2D Echocardiogram was done as his cardiovascular status was increasingly unstable and he was becoming more septic (WCC $43000 / \mathrm{mm}^{3}$ ). Furthermore, a cardiac murmur could clearly be heard.

2D echocardiogram revealed multiple vegetations on the mitral valve with grade III mitral regurgitation suggesting infective endocarditis.

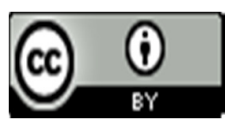

(C) 2016. Perera. This is an Open Access article distributed under the terms of the Creative Commons Attribution License (http: //creativecommons.org/licenses/by/4. 0), which permits unrestricted use, distribution, and reproduction in any medium, provided the original work is properly credited 
On the same day despite intensive treatment he suffered a cardiac arrest and could not be revived.

\section{Discussion}

This patient presented with sudden loss of consciousness one month after a head injury and intracranial surgery. Thus, the focus of attention had mainly being drawn to secondary cerebral haemorrhage and cerebral infection, and other common sources of infection such as chest infection causing sepsis. Although infective endocarditis may present as neurological deficit as the $1^{\text {st }}$ presentation, there was no evidence to suspect infective endocarditis until the $2^{\text {nd }} C T$ scan of the head after 48hours revealed extensive cerebral infarction. Renal impairment, pyrexia, and severe systemic inflammatory response he had, were non- specific and considered to be due to severe sepsis.

MCA embolic phenomenon ${ }^{7}$, and cerebrovascular complications ${ }^{6}$ and staphylococcal infection ${ }^{8}$ (especially multiresistant staphylococcus aureus) increase the risk of mortality related to infective endocarditis. The MCA territory is the most frequently affected arterial territory in patients with IE. Most develop partial middle cerebral artery (MCA) stroke, and a few presents with a complete MCA stroke ${ }^{5}$. It has been shown that, staphylococcus aureus infection has a significant relationship with the occurrence of a neurologic complications and death ${ }^{5}$. This patient suffered almost complete MCA stroke and had MRSA infection in blood culture. As with the case of this patient, mitral valve vegetation has been found to influence the occurrence of neurologic events with a higher risk ${ }^{1,5}$.

\section{Conclusions}

The presentation of this patient with infective endocarditis causing cerebral infraction was an unusual clinical scenario, as it followed traumatic brain injury and craniotomy. Many probable intracranial and extracranial complications of IE were not considered as those caused by infective endocarditis, as those complications were thought to be caused by his traumatic brain injury and secondary sepsis.

Infective endocarditis could be a cause of sudden neurological deterioration in some patients, especially, if they present with features of sepsis. Thus, high index of suspicion of IE is needed in such patients during the initial workup, to treat IE and to avoid devastating complications.

Acknowledgements: $\operatorname{Dr}$ K G D Hashini for summarising patient information.

\section{References}

1. Heiro M, Nikoskelainen J, Engblom E, et al. Neurologic manifestations of infective endocarditis: a 17-year experience in a teaching hospital in Finland. Arch Intern Med. 2000 Oct 9;160(18):2781-7.

http://dx.doi.org/10.1001/archinte.160.18.2781 PMid: 11025788

2. Aiesha Ahmed et al. Neurological Sequelae of Infectious Endocarditis, http://emedicine.medscape.com/article/1165712, Updated: Feb 17, 2016.

3. Adaya Weissler et al. Neurologic manifestations as presenting symptoms of endocarditis, IMAJ 2010; 12: 472-476. PMid:21337815

4. R'eza Behrouz. Preoperative Cerebrovascular Evaluation in Patients with Infective Endocarditis. Clin. Cardiol.2015; 38(7): 439 442.

http://dx.doi.org/10.1002/clc.22400

PMid:25872491

5. Sonneville R, Mourvillier B, Bouadma L, Wolff M. Management of neurological complications of infective endocarditis in ICU patients. Annals of Intensive Care. 2011;1:10

http://dx.doi.org/10.1186/2110-5820-1-10 PMid:21906336 PMCid:PMC3224466

6. Seung-Jae Lee, Sam-Sae Oh, Dal-Soo Lim, ChanYoung Na, Jae-Hyun Kim. Clinical significance of cerebrovascular complications in patients with acute infective endocarditis: a retrospective analysis of a 12-year single-center experience; BMC Neurology 2014; 14:30

http://dx.doi.org/10.1186/1471-2377-14-30 PMid:24528538 PMCid:PMC3928916

7. Bayer AS, Bolger AF, Taubert KA, et al. Diagnosis and management of infective endocarditis and its complications. Circulation 1998; 98:2936-2948.

http://dx.doi.org/10.1161/01.CIR.98.25.2936 PMid:9860802

8. Franck T, Disalvo G, Belliard O, Avierinos J-F et al. Risk of Embolism and Death in Infective Endocarditis: Prognostic Value of Echocardiography: A Prospective Multicenter Study, Circulation. 2005;112:69-75.

http://dx.doi.org/10.1161/CIRCULATIONAHA. 104.493155

PMid: 15983252 